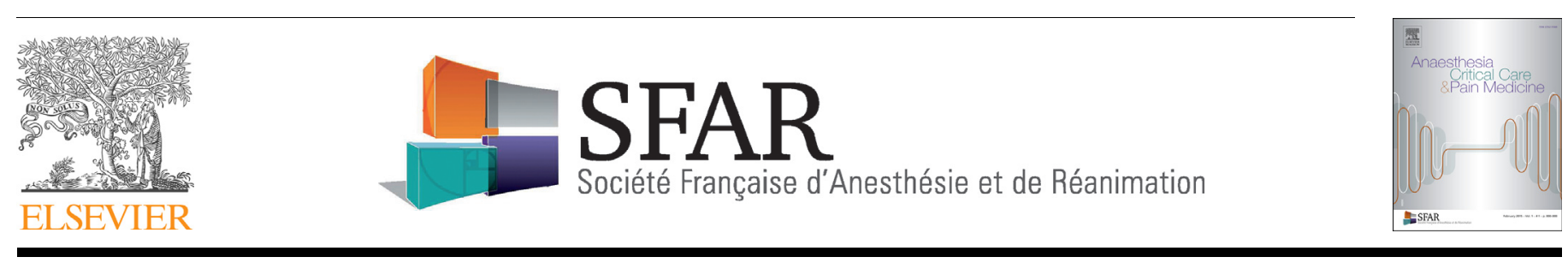

Original Article

\title{
Implementation of an electronic checklist in the ICU: Association with improved outcomes
}

\author{
Gary Duclos ${ }^{\mathrm{a}}$, Laurent Zieleskiewicz ${ }^{\mathrm{a}}$, François Antonini ${ }^{\mathrm{a}}$, Djamel Mokart ${ }^{\mathrm{b}}$, \\ Véronique Paone ${ }^{a}$, Marie Hélène Po ${ }^{a}$, Coralie Vigne ${ }^{a}$, Emmanuelle Hammad ${ }^{a}$, \\ Frédéric Potié $^{\mathrm{a}}$, Claude Martin ${ }^{\mathrm{a}}$, Sophie Medam ${ }^{\mathrm{a}}$, Marc Leone ${ }^{\mathrm{a}, *}$ \\ ${ }^{a}$ Service d'anesthésie et de réanimation, Aix-Marseille université, hôpital nord, Assistance publique-Hôpitaux de Marseille, 13015 Marseille, France \\ ${ }^{\mathrm{b}}$ Service d'anesthésie et de réanimation, institut Paoli-Calmettes, 13015 Marseille, France
}

\section{A R T I C L E I N F O}

\section{Article history:}

Available online 10 July 2017

\section{Keywords:}

Checklists

Nosocomial

Infection

Compliance

Guidelines

\begin{abstract}
A B S T R A C T
Objective: To assess the impact of an electronic checklist during the morning rounds on ventilatorassociated pneumonia (VAP) in the intensive care unit (ICU).

Patients and methods: We conducted a retrospective, before/after study in a single ICU of a university hospital. A systematic electronic checklist focusing on guidelines adherence was introduced in January 2012. From January 2008 to June 2014, we screened patients with ICU stay durations of at least 48 hours. Propensity score-matched analysis with conditional logistic regression was used to compare the rate of VAP and number of days free of invasive devices before and after implementation of the electronic checklist.

Results: We analysed 1711 patients (before group, $n=761$; after group, $n=950$ ). The rates of VAP were $21 \%$ and $11 \%$ in the before and after groups, respectively $(p<0.001)$. In propensity-score matched analysis ( $n=742$ in each group), VAP occurred in 151 patients (21\%) during the before period compared with 72 patients (10\%) during the after period (odds ratio $[\mathrm{OR}]=0.38$; 95\% confidence interval $[\mathrm{CI}]=0.27-0.53)$. The after group showed increases in ICU-free days $(\mathrm{OR}=1.05 ; 95 \% \mathrm{CI}=1.04-1.07)$ and mechanical ventilation-free days $(\mathrm{OR}=1.03 ; 95 \% \mathrm{CI}=1.01-1.04)$.

Conclusion: In this matched before/after study, implementation of an electronic checklist was associated with positive effects on patient outcomes, especially on VAP. Further prospective studies are needed to confirm these observations.

(c) 2017 Société française d'anesthésie et de réanimation (Sfar). Published by Elsevier Masson SAS. All rights reserved.
\end{abstract}

\section{Introduction}

Infectious complications remain a frequent issue in intensive care units (ICU), with the use of invasive devices representing the main risk factor $[1,2]$. Guidelines aim to improve practices, and thus reduce the risk of healthcare-related complications [3-6]. However, the adherence to guidelines is often suboptimal [7-9]. In a previous study, we observed a compliance rate of $24 \%$, and it was greatly reduced in patients requiring more than three clinical recommendations [10].

A number of strategies have been implemented to improve guideline adherence. For this purpose, a systematic electronic

\footnotetext{
* Corresponding author at: Service d'anesthésie et de réanimation, hôpital Nord, chemin des Bourrely, 13015 Marseille, France.

E-mail address: marc.leone@ap-hm.fr (M. Leone).
}

checklist was introduced in our ICU. Checklists are widely used in the operating room, and their implementation was reported to be associated with a reduced number of perioperative complications [11-14]. Some studies have reported encouraging findings regarding the impact of checklist implementation in the ICU [15-18]. In most studies, interventions target specific subgroups of patients or diseases [19-21], but their implementation results in improved adherence to guidelines [22,23].

Our hypothesis was that the implementation of an electronic checklist would reduce the rate of healthcare-related infections. The first goal of this study was to determine the effects of electronic checklist implementation on the rate of nosocomial ventilator-associated pneumonia (VAP). The secondary goals were to assess the durations of ICU stay, invasive mechanical ventilation, central venous catheterisation, and urinary catheterisation before and after checklist implementation. In another analysis of the 
completed checklist, we determined the compliance for each item to evaluate guideline adherence in our unit.

\section{Material and methods}

\subsection{Checklist data collection}

The electronic checklist combines the clinical recommendations initially extracted from our previous one-day survey [10] (Fig. 1). In the second step, a multi-professional group including physicians, certified registered nurse anesthetists (CRNA), nurses, and physiotherapists discussed each recommendation according to our local experience and challenges. The process required 3 months. Once the 14 recommendations had been defined, they were made available via an electronic program accessible to all ICU members via our intranet. After specific training using electronic tablets, four CRNAs (responsible for nursing care in our ICU) completed the electronic checklists for each patient at 07:00. The electronic checklists were immediately available to all of our staff via our intranet on computers, smartphones, and tablets, among others. During the morning rounds, the nurses, CRNAs, or residents reiterated the unresolved items from the electronic checklists.

The items on the electronic checklist covered invasive devices (central venous catheter, arterial catheter, peripheral venous line, urinary catheter) and their indications, VAP prevention (headof-bed elevation, tube cuff pressure control, ventilation pressure $<30 \mathrm{~cm} \mathrm{H}_{2} \mathrm{O}$, daily sedation interruption), physical rehabilitation (enteral feeding, enteral route, transfer from bed to armchair), and miscellaneous care (contention, type of mattress, antithrombotic prophylaxis).

We used a four-grade classification for each invasive device: "present and needed," "present and in excess," "present and probably in excess," or "none." "Present and in excess" was reported by the CRNAs during the 07:00 round. "Present and likely in excess" corresponded to an implemented device without any justification. The decision to attribute a grade for each item was left at the discretion of the CRNAs. Then, it was discussed with the staff, including physicians and nurses, or during ICU daily rounds. The usual recommendations were classified as: "done," "not done," or "not applicable."

\subsection{Patients}

From January 2008 to December 2014, we conducted a retrospective, before/after study in a 15-bed ICU of a 968-bed university hospital (Hôpital Nord, Marseille, France). Our checklist was introduced on January 1, 2012. The before period ranged from January 1,2008 , to December 31,2011 . The after period ranged from January 1, 2012 to December 31, 2014.

\subsection{Data collection}

Demographic and clinical features, including gender, age, simplified acute physiology score 2 (SAPS2), reason for admission, use of antibiotics in the first 48 hours, and immunological status (neutropenia, immunosuppressive therapeutics), were collected from our electronic database. We also collected the types of invasive devices used (venous central catheter, urinary catheter, tracheal intubation). We recorded the duration of use of each invasive device during the ICU stay, the duration of invasive mechanical ventilation, and the duration of ICU stay. We noted the reintubation rate and the ICU mortality rate. The numbers of ICUfree days and invasive device-free days (mechanical ventilation, central venous catheter, urinary catheter) were reported from day of admission or of exposure to day 28 or the day of death, as applicable.

Nosocomial infections included VAP, catheter-related infections, bacteraemia, and urinary catheter-related infection, as

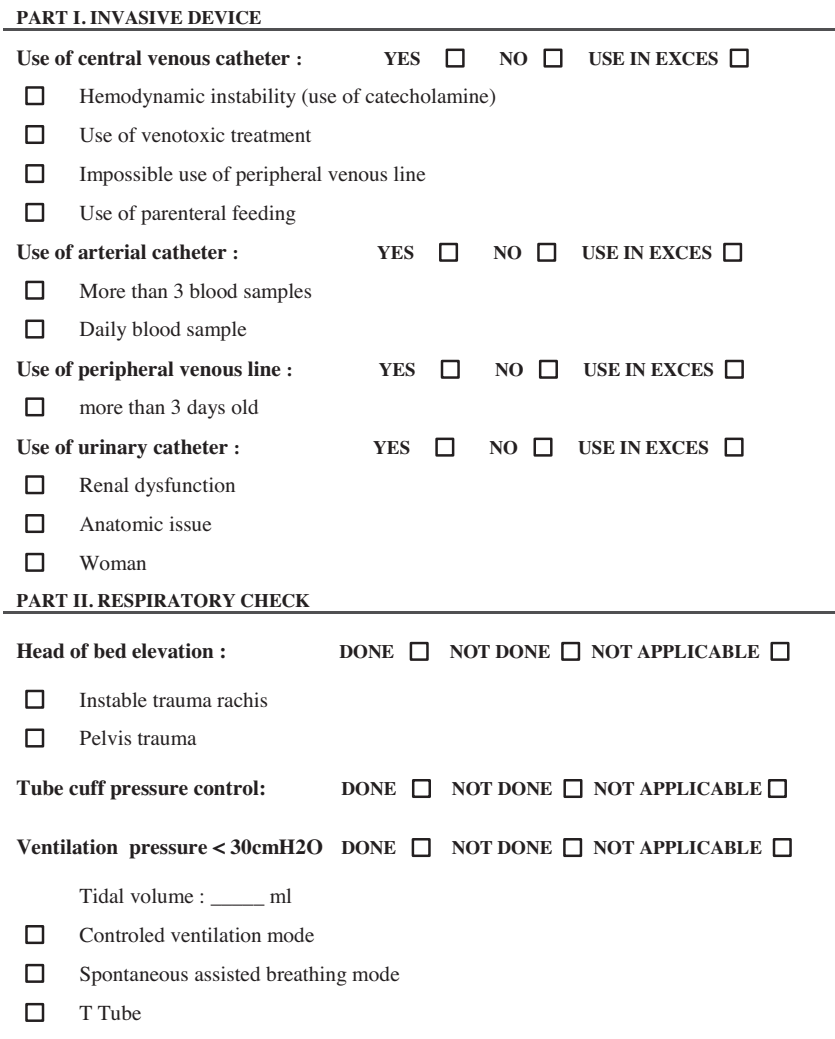

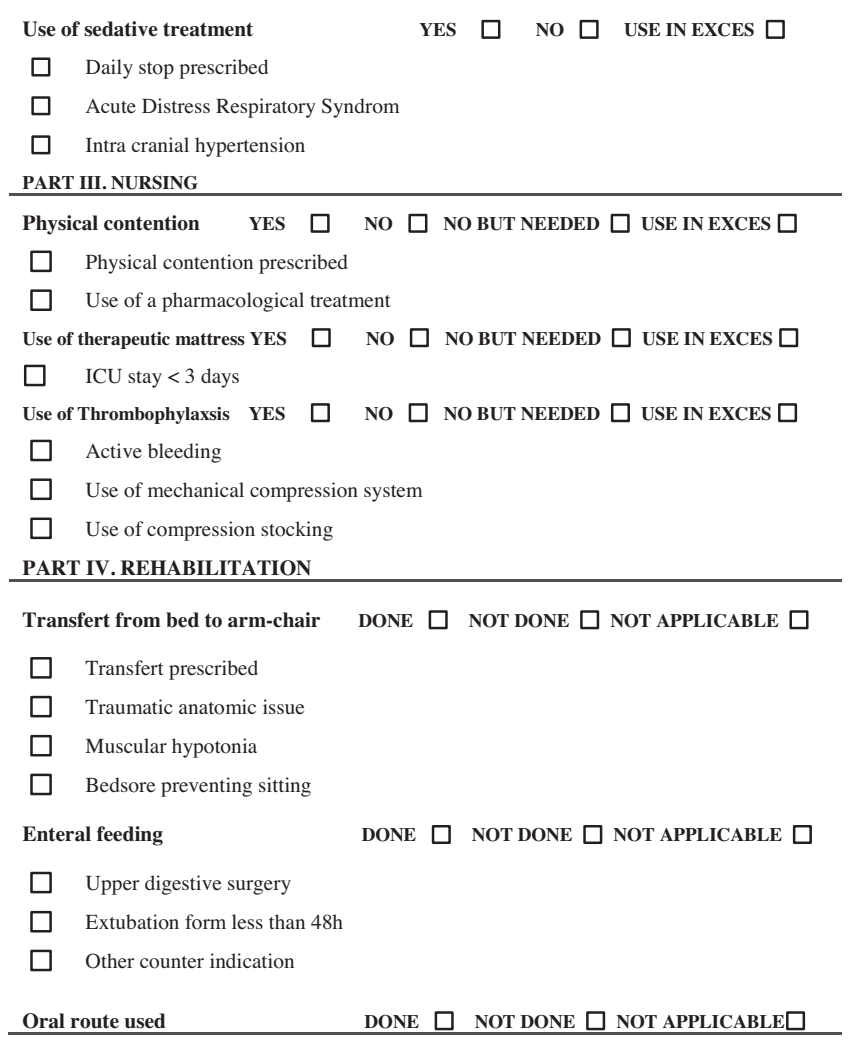

Fig. 1. Checklist used during study. 


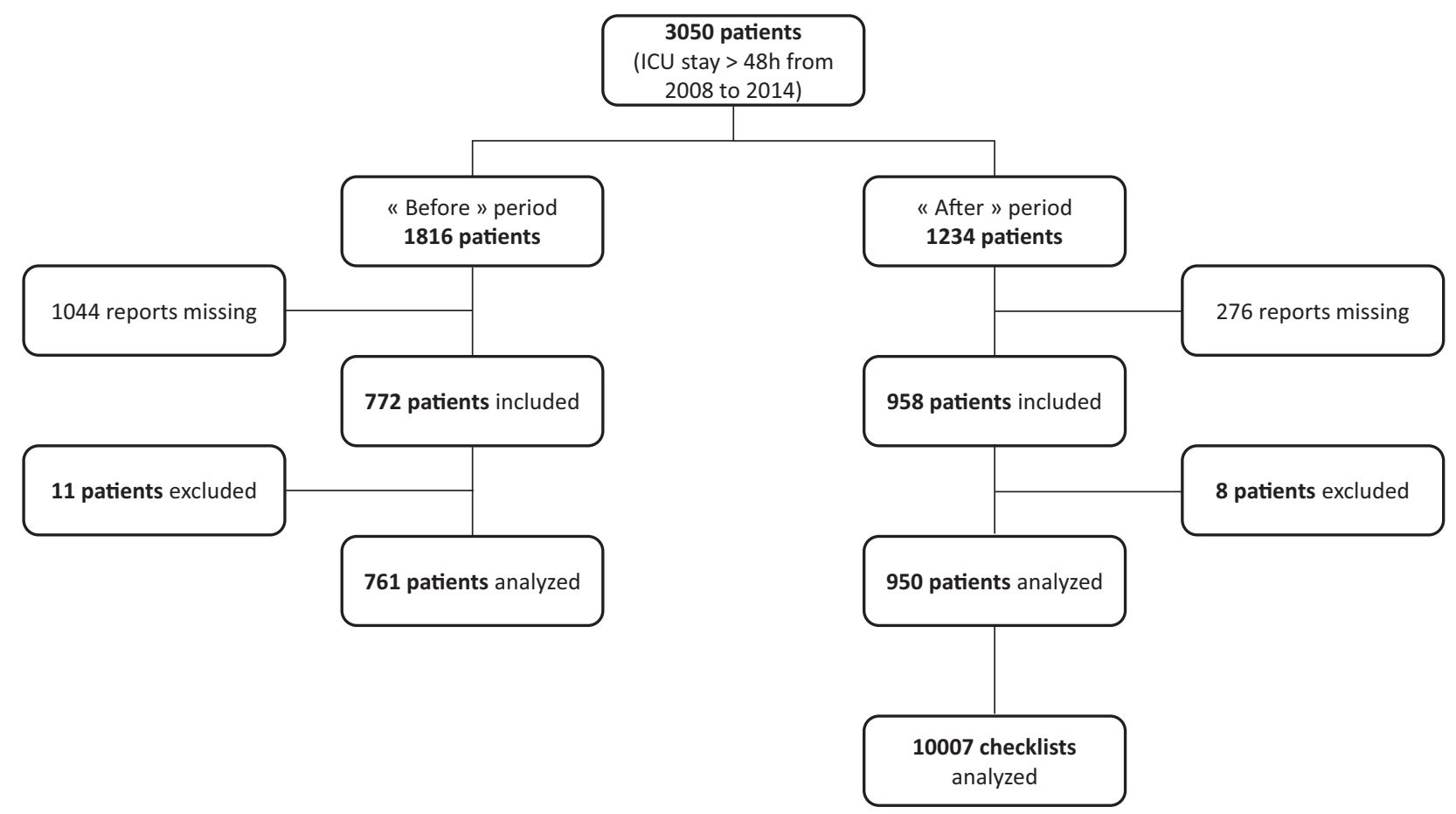

Fig. 2. Flowchart. ICU: intensive care unit.

defined according to international definitions [24] (Appendix A). Only episodes with microbiological identification were reported. We used our local data extracted from a regional database in which all patients admitted to our ICU for more than 48 hours were registered, and each of the previous nosocomial infections prospectively reported. The patients with data missing were excluded from the analysis (Fig. 2).

\subsection{Statistical analysis}

Statistical analyses were performed using IBM SPSS V24.0 (IBM Corp., Armonk, NY). The first analysis included all of the patients during each period. Continuous data are expressed as means and standard deviations or medians with interquartiles. Qualitative data are expressed as absolute numbers and percentages. Comparisons between the continuous data periods were performed using Student's $t$ test or Wilcoxon's test according to their distribution and with the chi-square test for categorical variables. A propensity score-based approach was used to match patients between the periods. Propensity score was derived with the following covariates: age, SAPS2, reason for admission (trauma, medical, scheduled or emergent surgery), sex, and immunological status. A 1:1 matching algorithm without replacement was used with a maximum range of standard deviation of $20 \%$ (Appendix B). Outcomes were compared between 1444 matched patients (722 in each group) using conditional logistic regression. Results are presented as odds ratios (OR) with 95\% confidence intervals (95\% CI). All comparisons were two-tailed and $P<0.05$ was required to exclude the null hypothesis. To reduce the effect of early death, we computed the numbers of ICU-free days and device (tracheal intubation, central line, urinary catheter)-free days (from inclusion to day 28).

As this was an observational retrospective study, according to French legislation (articles L. 1121-1 paragraph 1 and R. 1121-2, Public Health Code), neither informed consent nor approval from the ethics committee was needed to use routine data at the time of the analysis. Patients or their families were informed that data could be used during their ICU stay. Data were stocked and treated according CNIL authorisation number 588909v1.

\section{Results}

During the entire study period, 3050 patients were admitted to our ICU for more than 48 hours, including 1816 patients in the before group and 1234 patients in the after group. Among these patients, 1730 reports were available in the regional database on nosocomial infections (Regional Surveillance Network of Healthcare-acquired Infections, C-CLIN Sud-Est). Unavailable data were explained by incomplete reports during the study period. Of the 1730 available reports, 19 patients were excluded due to missing data (incomplete or erroneous forms). Finally, 761 and 950 patients were respectively included in the before and after groups, (Fig. 2). We also analysed 10,007 electronic checklists of the 950 patients in the after group. Central venous catheter, arterial catheter, and urinary catheter uses were reported as definitely in excess or probably in excess (no clear indication) in $16 \%, 7.6 \%$, and $27 \%$ of our patients, respectively. Among the patients eligible for each guideline, head-of-bed elevation, daily interruption of sedation, armchair transfer, and enteral feeding non-compliance were found in $1.2 \%, 32 \%, 28 \%$, and $21 \%$ of the electronic checklists, respectively.

Univariate analysis showed imbalances between the two groups (Table 1, Fig. 3). The patients in the after group were older and had higher severity scores than those in the before group. Immunosuppression was more frequent in the after group. The case mix differed between the two periods. The rates of patients requiring emergency and scheduled surgery increased in the after period, whereas the rates of medical and trauma patients decreased (Table 1). There were no significant differences between analysed patients and patients with missing reports in terms of demographic characteristics, case mix, or death (Table 1). Data regarding the duration of ICU stay of the patients who were not analysed were missing from the before period. We did not have access to specific ICU duration data as the institution's computer program saved only total length of hospitalisation stay for this 
Table 1

Comparison of patients characteristics according to the period group.

\begin{tabular}{|c|c|c|c|c|c|}
\hline \multirow[t]{2}{*}{ Variables } & \multicolumn{2}{|c|}{ "Before period" } & \multicolumn{2}{|c|}{ "After period" } & \multirow[t]{2}{*}{$P$} \\
\hline & $\begin{array}{l}\text { All patients } \\
(n=1816)\end{array}$ & $\begin{array}{l}\text { Analysed group } \\
(n=750)\end{array}$ & $\begin{array}{l}\text { All patients } \\
(n=1234)\end{array}$ & $\begin{array}{l}\text { Analysed group } \\
(n=961)\end{array}$ & \\
\hline Age (years) (median [Q25-Q75]) & 55 [39-67] & 54 [39-67] & 56 [37-68] & $58[42-69]$ & 0.005 \\
\hline Death occurring (\%) & $360(20)$ & $169(23)$ & $257(21)$ & $205(21)$ & 0.6 \\
\hline SAPS2 at admission & $40[29-53]$ & $40[15-65]$ & $41[30-52]$ & $41[19-63]$ & $<0.001$ \\
\hline Males (\%) & $1323(73)$ & $532(71)$ & $856(69.3)$ & $655(68)$ & 0.23 \\
\hline Immunosuppression (\%) & - & $46(6.1)$ & - & $110(11)$ & $<0.001$ \\
\hline Trauma patients (\%) & $726(40)$ & $309(41)$ & $432(35)$ & $336(35)$ & 0.009 \\
\hline Medical patients (\%) & $544(30)$ & $232(31)$ & $296(24)$ & $235(24)$ & 0.003 \\
\hline Emergent surgery patients (\%) & $327(18)$ & $126(17)$ & $284(23)$ & $213(22)$ & 0.006 \\
\hline Scheduled surgery patients (\%) & $236(13)$ & $90(12)$ & $210(17)$ & $177(18)$ & $<0.001$ \\
\hline Duration of ICU stay (days) & - & $15 \pm 18$ & $11 \pm 8$ & $11 \pm 15$ & 0.005 \\
\hline Invasive mechanical ventilation (\%) & - & $613(82)$ & - & $742(77)$ & 0.026 \\
\hline Re-intubation (\%) & - & $146(20)$ & - & $127(13)$ & $<0.001$ \\
\hline Central venous catheter exposure (\%) & - & $524(70)$ & - & $709(74)$ & 0.082 \\
\hline Urinary catheter exposure (\%) & - & $655(87)$ & - & $902(94)$ & $<0.001$ \\
\hline
\end{tabular}

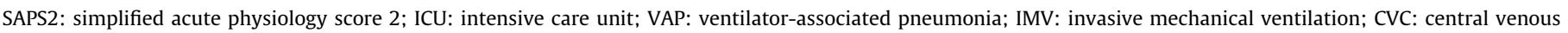
catheter; CAUTI: catheter-associated urinary tract infection.
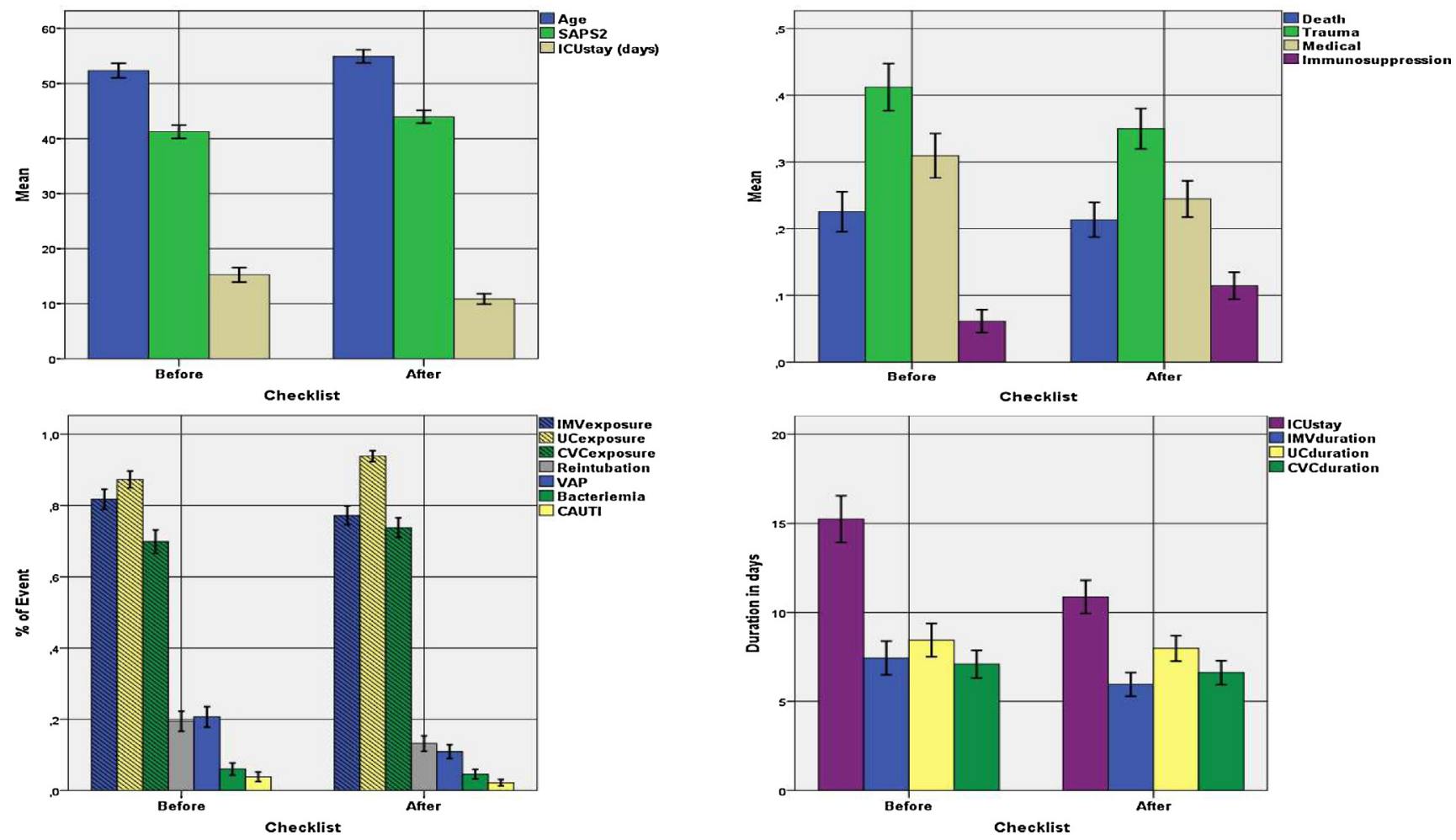

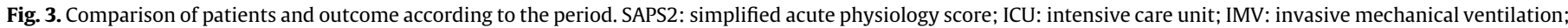
CVC: central venous catheter; UC: urinary catheter; VAP: ventilator associated pneumonia; CAUTI: catheter associated urinary tract infection.

period. Exposure to mechanical ventilation decreased during the after period, which was due to patients admitted after emergency surgery. In contrast, exposure to urinary catheter use increased during the after period. The rates of reintubation were $20 \%$ in the before group and $13 \%$ in the after group $(P<0.001)$ (Table 1, Fig. 3 ).

The durations of use of each invasive device are shown in Fig. 3. The duration of ICU stay was significantly reduced in the after group ( $15 \pm 18$ days $v s$. $11 \pm 15$ days in the before group, $P=0.005$ ) (Fig. 3). The duration of invasive mechanical ventilation decreased from $7.4 \pm 13$ days in the before group to $6.0 \pm 10$ days $(P=0.01)$ in the after group (Fig. 3). The durations of exposure to urinary catheter and central venous catheter use were similar between the two groups (Fig. 3, Table 2).
The rates of VAP were $21 \%$ and $11 \%$ in the before and after groups, respectively $(P<0.001)$. Central venous catheter-related infection, bacteremia, and catheter-related urinary tract infection rates did not differ between the two groups. The mortality rates were similar in the two groups ( $23 \%$ vs. $21 \%$, respectively, $P=0.6$ ) (Table 1). The outcomes are shown according to the year in Table 3 , Fig. 4, and Fig. 5.

In the propensity-based score, we matched 722 patients for each period (Table 3). Conditional logistic regression indicated a reduction in the risk of VAP associated with the checklist period ( $\mathrm{OR}=0.38 ; 95 \% \mathrm{CI}=0.27-0.53 ; P<0.001)$. Secondary outcome analysis showed increases in ICU-free days ( $16 \pm 8.5$ vs. $19 \pm 7.5$; $P<0.001)$ and ventilator-free days $(21.5 \pm 7.8$ vs. $23 \pm 6.6$; 
Table 2

Comparison of outcome depending of the year.

\begin{tabular}{|c|c|c|c|c|c|}
\hline \multirow{2}{*}{$\frac{\text { Year }}{2008}$} & \multicolumn{2}{|l|}{ Variables } & \multirow{2}{*}{$\frac{\text { Year }}{2011}$} & \multicolumn{2}{|l|}{ Variables } \\
\hline & VAP (\%) & $59(25.2)$ & & VAP (\%) & $48(20.9)$ \\
\hline \multirow[t]{7}{*}{$n=234$} & CAUTI $(\%)$ & $19(8.1)$ & $n=230$ & CAUTI $(\%)$ & $5(2.2)$ \\
\hline & Bacteraemia (\%) & $8(3.4)$ & & Bacteraemia (\%) & $19(8.2)$ \\
\hline & Death $(\%)$ & $50(21.3)$ & & Death $(\%)$ & $54(23.5)$ \\
\hline & Duration ICU stay (days) & $16.1 \pm 17.4$ & & Duration ICU stay (days) & $14.4 \pm 18.1$ \\
\hline & IMV exposure (days) & $8.6 \pm 13.3$ & & IMV exposure (days) & $7.5 \pm 15$ \\
\hline & UC exposure (days) & $8.4 \pm 9.7$ & & UC exposure (days) & $9.2 \pm 15.2$ \\
\hline & CVC exposure (days) & $7.4 \pm 10.0$ & & CVC exposure (days) & $7.8 \pm 11.1$ \\
\hline 2009 & VAP (\%) & $23(16.5)$ & 2012 & $\operatorname{VAP}(\%)$ & $60(16)$ \\
\hline \multirow[t]{7}{*}{$n=139$} & CAUTI $(\%)$ & $2(1.4)$ & $n=375$ & CAUTI $(\%)$ & $9(2.4)$ \\
\hline & Bacteraemia (\%) & $7(5)$ & & Bacteraemia (\%) & $18(4.8)$ \\
\hline & Death $(\%)$ & $29(20.9)$ & & Death $(\%)$ & $91(24.2)$ \\
\hline & Duration ICU stay (days) & $15 \pm 18.3$ & & Duration ICU stay (days) & $11.3 \pm 12$ \\
\hline & IMV exposure (days) & $6.5 \pm 11.2$ & & IMV exposure (days) & $6.4 \pm 10.2$ \\
\hline & UC exposure (days) & $8.0 \pm 14$ & & UC exposure (days) & $8.8 \pm 11.6$ \\
\hline & CVC exposure (days) & $5.7 \pm 11.9$ & & CVC exposure (days) & $7.2 \pm 11.4$ \\
\hline 2010 & $\operatorname{VAP}(\%)$ & $25(17)$ & 2013 & $\operatorname{VAP}(\%)$ & $34(8.5)$ \\
\hline \multirow[t]{7}{*}{$n=147$} & CAUTI $(\%)$ & $3(1.4)$ & $n=398$ & CAUTI $(\%)$ & $10(2.6)$ \\
\hline & Bacteraemia (\%) & $11(7.5)$ & & Bacteraemia (\%) & $18(4.4)$ \\
\hline & Death $(\%)$ & $36(24.5)$ & & Death $(\%)$ & $73(18.5)$ \\
\hline & Duration ICU stay (days) & $15.3 \pm 19.7$ & & Duration ICU stay (days) & $11.3 \pm 17.9$ \\
\hline & IMV exposure (days) & $6.3 \pm 11.6$ & & IMV exposure (days) & $6.1 \pm 11.5$ \\
\hline & UC exposure (days) & $7.7 \pm 12.8$ & & UC exposure (days) & $7.8 \pm 12.1$ \\
\hline & CVC exposure (days) & $6.9 \pm 10.6$ & & CVC exposure (days) & $6.4 \pm 10.7$ \\
\hline 2014 & VAP (\%) & $11(5.2)$ & & & \\
\hline \multirow[t]{7}{*}{$n=188$} & CAUTI $(\%)$ & $2(1)$ & & & \\
\hline & Bacteraemia (\%) & $8(4.4)$ & & & \\
\hline & Death $(\%)$ & $41(22)$ & & & \\
\hline & Duration ICU stay (days) & $8.23 \pm 8.2$ & & & \\
\hline & IMV exposure (days) & $4.5 \pm 6.4$ & & & \\
\hline & UC exposure (days) & $6.4 \pm 7.0$ & & & \\
\hline & CVC exposure (days) & $5.8 \pm 8.3$ & & & \\
\hline
\end{tabular}

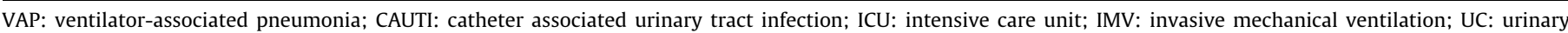
catheter; CVC: central venous catheter.

Table 3

Characteristics and outcomes of patients depending of matching.

\begin{tabular}{|c|c|c|c|c|}
\hline \multirow[t]{2}{*}{ Variables } & \multicolumn{2}{|c|}{ Before matching } & \multicolumn{2}{|l|}{ After matching } \\
\hline & $\begin{array}{l}\text { Before group } \\
(n=750)\end{array}$ & $\begin{array}{l}\text { After group } \\
(n=961)\end{array}$ & $\begin{array}{l}\text { Before group } \\
(n=722)\end{array}$ & $\begin{array}{l}\text { After group } \\
(n=722)\end{array}$ \\
\hline Age (years) (median [Q25-Q75]) & 54 [39-67] & 58 [42-69] & 55 [40-67] & 58 [41-69] \\
\hline Death occurring (\%) & $169(23)$ & $205(21)$ & $167(23)$ & $151(21)$ \\
\hline SAPS2 (at admission) & $40[15-65]$ & $41[19-63]$ & $40[29-54]$ & $41[31-52]$ \\
\hline Males (\%) & $532(71)$ & $655(68)$ & $510(71)$ & $490(68)$ \\
\hline Immunosuppression (\%) & $46(6.1)$ & $110(11)$ & $46(6.5)$ & $44(6.1)$ \\
\hline Trauma patients $(\%)$ & $309(41)$ & $336(35)$ & $296(41)$ & $279(38.5)$ \\
\hline Medical patients (\%) & $232(31)$ & $235(24)$ & $219(30)$ & $191(26.5)$ \\
\hline Emergent surgery patients (\%) & $126(17)$ & $213(22)$ & $126(17.5)$ & $135(18.5)$ \\
\hline Scheduled surgery patients (\%) & $90(12)$ & $177(18)$ & $81(11)$ & $117(16)$ \\
\hline ICU-free days & $19[10-23]$ & $22[17-24]$ & $19[10-23]$ & $22[17-24]$ \\
\hline Invasive mechanical ventilation (\%) & $613(82)$ & $742(77)$ & $600(83)$ & $552(76.5)$ \\
\hline Ventilation-free days & 25 [19-27] & $26[21-28]$ & 25 [19-27] & $26[21-28]$ \\
\hline Re-intubation (\%) & $146(20)$ & $127(13)$ & $143(20)$ & $95(13)$ \\
\hline Central venous catheter exposure (\%) & $524(70)$ & $709(74)$ & $514(71)$ & $528(73)$ \\
\hline CVC-free days & $24[19-28]$ & $25[21-28]$ & $24[19-28]$ & $25[21-28]$ \\
\hline Urinary catheter exposure (\%) & $655(87)$ & $902(94)$ & $647(89.5)$ & $666(92)$ \\
\hline UC-free days & $23[18-26]$ & $24[19-26]$ & $23[18-26]$ & $24[19-26]$ \\
\hline
\end{tabular}

$P<0.001)$ during the checklist period. The occurrence rates of death, CVC infection, bacteraemia, and catheter-associated urinary tract infection (CAUTI) were different between periods (Table 4).

\section{Discussion}

In our cohort, the implementation of an electronic checklist was associated with a significant reduction in the rate of VAP. The electronic checklist seemed to influence guideline adherence with regard to daily sedation interruption and head-of-bed elevation, and improved the global management of invasive devices, resulting in lower nosocomial infection rates and shorter periods of invasive device exposure.

Adherence to guidelines is a crucial issue in the ICU. Application of care bundles was shown to be associated with improved performance [4,6,25-27]. However, most guidelines are based on targeted strategies with specific goals [1,28-31]. Routinely, we observed a low rate of compliance to guidelines in patients eligible for at least three clinical recommendations [10]. It seems that the more complex the care strategy, the more omissions occur. This is 


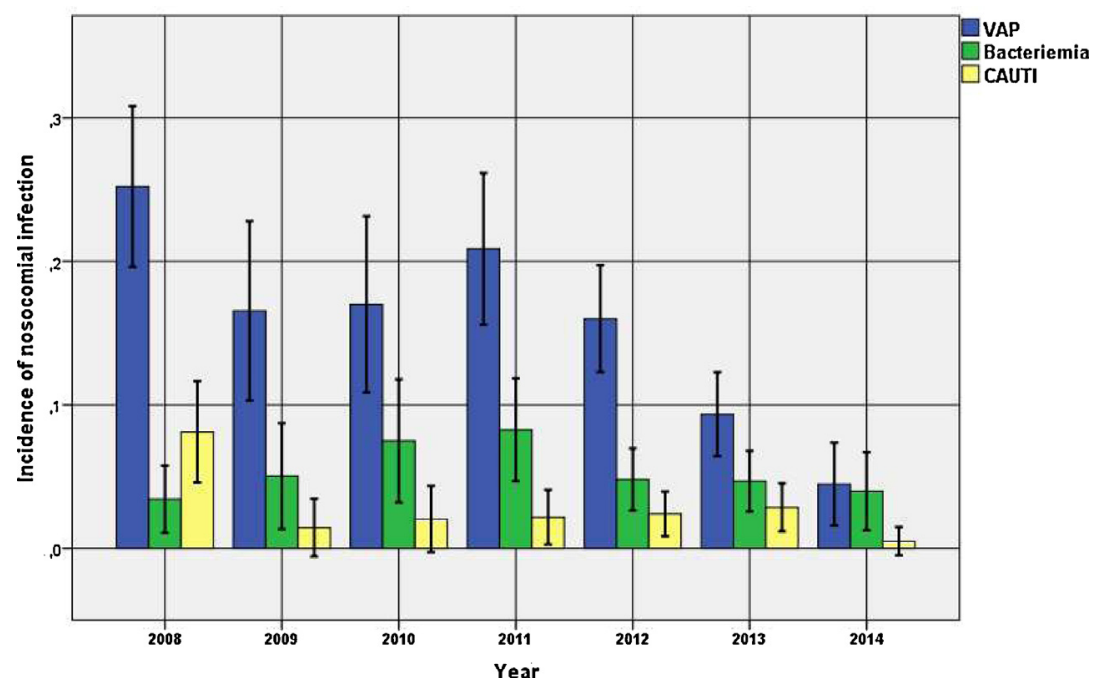

Fig. 4. Incidence of nosocomial infection according to the year. VAP: ventilator associated pneumonia; CAUTI: catheter associated urinary tract infection.

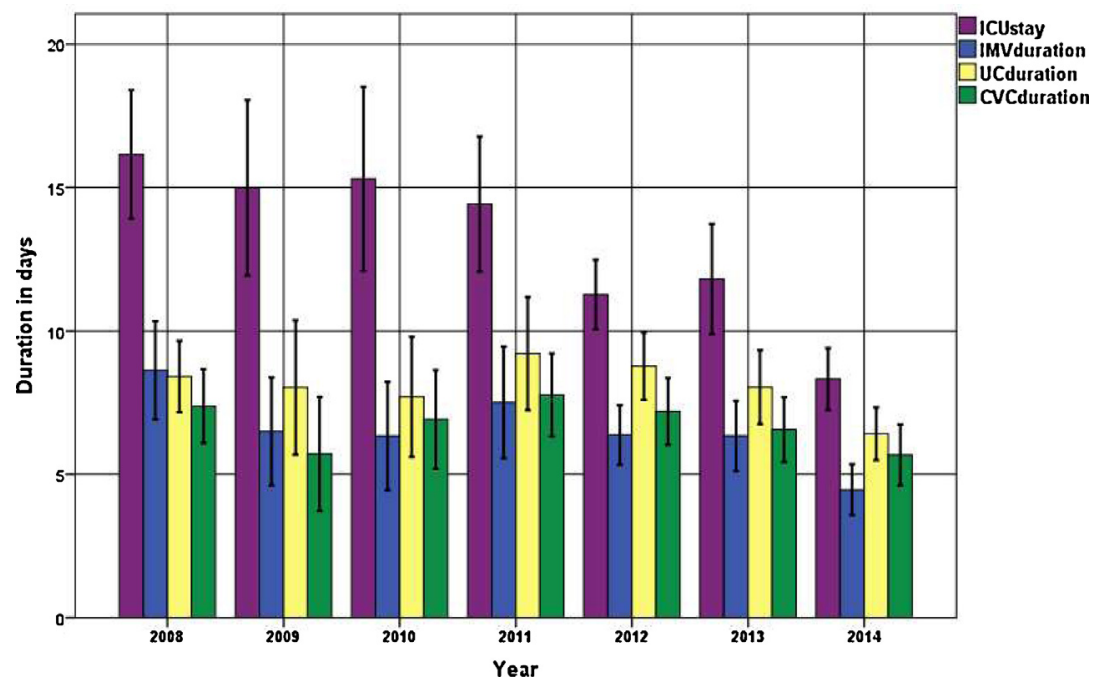

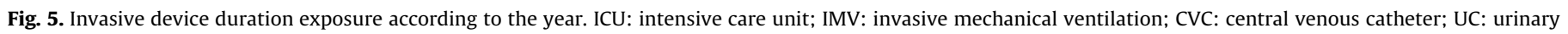
catheter.

Table 4

Results of outcome analyses of matched cohort.

\begin{tabular}{|c|c|c|c|c|}
\hline Outcome & $\begin{array}{l}\text { "Before" group } \\
(n=722)\end{array}$ & $\begin{array}{l}\text { “After” group } \\
(n=722)\end{array}$ & OR $(95 \% \mathrm{CI})$ & $P$ \\
\hline Death (\%) & $167(23)$ & $151(21)$ & $0.93[0.78-1.12]$ & 0.47 \\
\hline $\operatorname{VAP}(\%)$ & $151(21)$ & $72(10)$ & $0.38[0.27-0.53]$ & $<0.001$ \\
\hline CVC infection (\%) & $4(0.5)$ & $3(0.3)$ & $0.42[0.09-2.73]$ & 0.42 \\
\hline Bacteraemia (\%) & $45(6.2)$ & $32(4.4)$ & $0.69[0.43-1.11]$ & 0.13 \\
\hline CAUTI $(\%)$ & $28(3.9)$ & $20(2.8)$ & $0.73[0.39-1.26]$ & 0.24 \\
\hline Re-intubation rate (\%) & $143(20)$ & $95(13)$ & $0.76[0.61-0.95]$ & 0.02 \\
\hline ICU-free days & $16(8.5)$ & $19(7.5)$ & $1.05[1.04-1.07]$ & 0.001 \\
\hline Ventilator-free days & $21.5(7.8)$ & $23(6.6)$ & $1.03[1.01-1.04]$ & 0.001 \\
\hline CVC-free days & $21.5(7.7)$ & $22.3(7)$ & $1.01[1.00-1.03]$ & 0.03 \\
\hline UC-free days & $20.5(7.8)$ & $21.3(7)$ & $1.01[1.00-1.03]$ & 0.06 \\
\hline
\end{tabular}

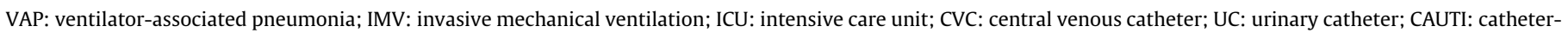
associated urinary tract infection. Continuous data are reported as mean (SD).

why our electronic checklist aimed to cover a wide spectrum of clinical areas.

Whereas the implementation of checklists indicated its efficiency in the operating room [11-13], its use in the ICU remains to be defined. Previous single-center studies showed improved guideline compliance and decreased use of invasive devices after checklist implementation [15,16]. Conroy et al. reported a validation process using the Delphi method from a multidisciplinary workgroup of local experts [32,33]. This method served to select the most relevant items. In our institute, a multiprofessional group including CRNAs, nurses, physicians, and therapists developed a global checklist. The rationale was based 
on the results of a large one-day survey [10]. In all cases, the contents of checklists should generate discussion about the processes of care with all members of the care team [17,34].

In our opinion, checklists should be widely adopted. We used electronic support, which was easily accessible by the entire staff via our intranet. A previous study by Kastrup et al. showed that adherence to guidelines could be improved by using an electronic tool [35]. Weiss et al. showed that prompting checklist use during the morning rounds was associated with better compliance [18]. We did not assess the rate of daily use of our electronic checklist. However, our system collected more than 10,000 checklists during the study period, generating an efficient tool for assessing our practice.

The findings regarding use of the electronic checklist were encouraging. After its implementation, the incidence of VAP statistically decreased. As compared with other studies, this incidence seemed moderately high [1-3]. This could be explained by the inclusion of patients hospitalised for at least 48 hours, trauma patients with head injuries, and patients developing complications after chest surgery. Exposure to invasive mechanical ventilation may also have been decreased due to the increase in post-surgical patient admission. During the study period, there were no changes in rates of CAUTI, bloodstream infection, or catheter-related infection. As the severity status of our patients increased, the lack of increases in these specific infections may reflect improved practice. Moreover, CAUTI and catheter-related infection rates were already low in the before period, and any influence on the electronic checklist could be masked by a lack of study power. We conducted several previous studies regarding urinary catheter use in the field [36]. Thus, improvement was probably difficult because efforts had previously been made to reduce the duration of urinary catheterisation. These findings highlight a possible link between the local culture of the ICU and quality of care $[37,38]$.

Analysis of the 10,007 checklists underlined that our practices can still be improved. The daily interruption of sedation, the route of feeding, or armchair transfer was applied in around $70-80 \%$ of our cases. Invasive devices were considered to be unjustified in $7.6 \%$ to $27 \%$ of cases. For example, as in a previous study, we found about $20 \%$ of urinary catheter use was in excess [33]. The physician in charge can justify or tolerate a process considered in excess by the CRNA during their morning rounds. It should be noted that the goal of the checklist was to introduce discussion regarding care quality. This discrepancy is representative of a disparity between routine practice and guidelines.

Our study had several limitations. First, its retrospective design led to the exclusion of several patients due to incomplete data, although demographic characteristics were the same between patients with missing reports and those included in the analyses. The large number of missing data can lead to selection bias. We compared some available demographic data and found no significant differences. VAP reduction could be induced by the Hawthorne effect, but the main goal of an electronic checklist was to improve guideline adherence, directly influencing physician practice, and prompting discussion with the medical team. However, with this retrospective study, the staffs were not influenced by the observer effect. Our results reflect real-life practice. Furthermore, analysing device-free days seems more accurate than the crude duration of exposure as it removes the effect of early death during an ICU stay. Second, the case mix evolved during the study period with the implementation of chest surgery in our hospital in June 2009 and the consequent increase in the number of post-surgical patients, but the propensity scorematched analysis should have reduced possible effects. Third, the management of patients probably differed between the onset and completion of the study considering the long period included.

\section{Conclusion}

In conclusion, the implementation of an electronic checklist seems associated with positive effects on the patients' outcome. The difference observed the two studied period suggest that use of a daily electronic checklist may have reduced nosocomial ventilator-associated pneumonia. These results require a prospective and multi-centered study in order to evaluate the impact of checklist use in ICU.

\section{Ethical statement}

We further confirm that any aspect of the work covered in this manuscript that has involved either experimental animals or human patients has been conducted with the ethical approval of all relevant bodies and that such approvals are acknowledged within the manuscript.

\section{Funding}

No financial support.

\section{Disclosure of interest}

The authors declare that they have no competing interest.

\section{Acknowledgments}

Thanks to Dr Suzanna Zgorska-Moussa for her help in the translation of this manuscript.

\section{Appendix A. Criteria for defining infections (based on international definitions) [24].}

\begin{tabular}{|c|c|}
\hline Site & Criteria for diagnosis \\
\hline $\begin{array}{l}\text { Catheter-associated } \\
\text { urinary tract infection }\end{array}$ & $\begin{array}{l}\text { Positive urine culture }\left(>10^{4} \text { bacteria/ml, no more }\right. \\
\text { than two bacteria) AND Fever (body } \\
\text { temperature }>38^{\circ} \mathrm{C} \text { ) without any other } \\
\text { suspected infection site }\end{array}$ \\
\hline Bacteraemia & $\begin{array}{l}\text { At least one positive blood culture collected } \\
\text { during fever episode excepted for negative } \\
\text { coagulase Staphylococcus, Bacillus sp., } \\
\text { Corynebacterium sp., Propionibacterium sp., } \\
\text { Micrococcus sp. For those micro-organisms, two } \\
\text { positive blood cultures collected at different sites are } \\
\text { required }\end{array}$ \\
\hline Catheter-related infection & $\begin{array}{l}\text { Positive blood culture (collected by a venous } \\
\text { puncture) } \\
\text { AND one of the following criteria: } \\
\text { 1. Local infection AND identification of the same } \\
\text { micro-organism in pus and peripheral blood } \\
\text { 2. Positive culture of catheter AND identification } \\
\text { of the same micro-organism in peripheral blood }\end{array}$ \\
\hline $\begin{array}{l}\text { Ventilator-associated } \\
\text { pneumonia }\end{array}$ & $\begin{array}{l}\text { Evolving radiological lung opacity } \\
\text { AND identification of micro-organism in: } \\
\text { 1. Tracheal aspirates through endotracheal tube } \\
\text { with at least } 10^{6} \text { colonies forming unit/ml OR } \\
\text { 2. Bronchial-alveolar lavage with at least } 10^{4} \\
\text { colonies forming unit/ml OR } \\
\text { 3. Protected brush with at least } 10^{3} \text { colonies } \\
\text { forming unit/ml OR } \\
\text { 4. Collection of abscess or pleural fluid }\end{array}$ \\
\hline Intra-abdominal infection & $\begin{array}{l}\text { Pus or abscess collected during surgery } \\
\text { OR positive blood culture collected at the onset of } \\
\text { disease }\end{array}$ \\
\hline
\end{tabular}


Appendix A (Continued)

Site

Tissue or skin infection

Criteria for diagnosis

Presence of at least two of the following signs: Local pain, tumefaction, local heat, sensibility, redness

AND at least one of the following signs:

1. Positive culture of micro-organism collected at the suspected site

2. Micro-organism identified in blood culture

Appendix B. Effect of matching on standardized difference.

\section{Standardized differences before matching}

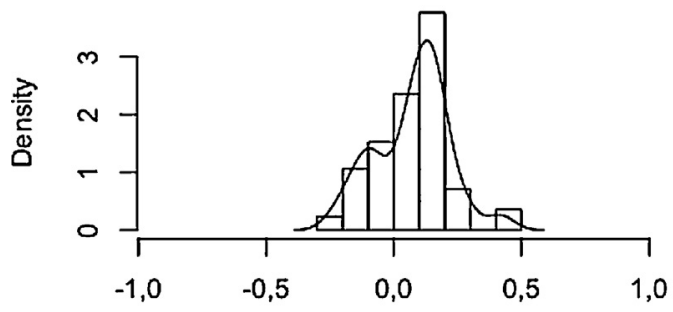

Std. difference

\section{Standardized differences after matching}

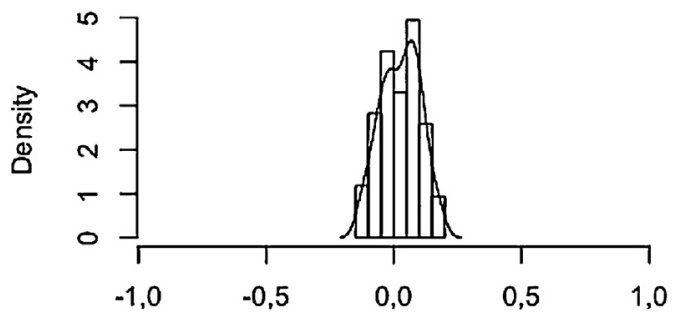

Std. difference

\section{References}

[1] Mietto C, Pinciroli R, Patel N, Berra L. Ventilator associated pneumonia: evolving definitions and preventive strategies. Respir Care 2013;58:9901007. http://dx.doi.org/10.4187/respcare.02380.

[2] Vincent J-L, Rello J, Marshall J, Silva E, Anzueto A, Martin CD, et al. International study of the prevalence and outcomes of infection in intensive care units. JAMA 2009;302:2323-9. http://dx.doi.org/10.1001/jama.2009.1754.

[3] Morris AC, Hay AW, Swann DG, Everingham K, McCulloch C, McNulty J, et al. Reducing ventilator-associated pneumonia in intensive care: impact of implementing a care bundle. Crit Care Med 2011;39:2218-24. http://dx.doi.org/ 10.1097/CCM.0b013e3182227d52.

[4] Hazamy PA, Haley VB, Tserenpuntsag B, Tsivitis M, Giardina R, Knab R, et al. Effect of 2013 National Healthcare Safety Network definition changes on central line bloodstream infection rates: Audit results from the New York State Department of Health. Am J Infect Control 2015;43:280-2. http:// dx.doi.org/10.1016/j.ajic.2014.11.011.

[5] Chenoweth C, Saint S. Preventing catheter-associated urinary tract infections in the intensive care unit. Crit Care Clin 2013;29:19-32. http://dx.doi.org/ 10.1016/j.ccc.2012.10.005.

[6] Neelakanta A, Sharma S, Kesani VP, Salim M, Pervaiz A, Aftab N, et al. Impact of changes in the NHSN catheter-associated urinary tract infection (CAUTI) surveillance criteria on the frequency and epidemiology of CAUTI in intensive care units (ICUs). Infect Control Hosp Epidemiol 2015;36:346-9. http:// dx.doi.org/10.1017/ice.2014.67.

[7] Cabana MD, Rand CS, Powe NR, Wu AW, Wilson MH, Abboud PA, et al. Why don't physicians follow clinical practice guidelines? A framework for improvement. JAMA 1999;282:1458-65.

[8] Flodgren G, Conterno LO, Mayhew A, Omar O, Pereira CR, Shepperd S. Interventions to improve professional adherence to guidelines for prevention of device-related infections. Cochrane Database Syst Rev 2013;3:CD006559. http://dx.doi.org/10.1002/14651858.CD006559.pub2.
[9] Quenot J-P, Mentec H, Feihl F, Annane D, Melot C, Vignon P, et al. Bedside adherence to clinical practice guidelines in the intensive care unit: the TECLA study. Intensive Care Med 2008;34:1393-400. http://dx.doi.org/10.1007/ s00134-008-1059-y.

10] Leone M, Ragonnet B, Alonso S, Allaouchiche B, Constantin J-M, Jaber S, et al. Variable compliance with clinical practice guidelines identified in a 1-day audit at 66 French adult intensive care units. Crit Care Med 2012;40:3189-95 http://dx.doi.org/10.1097/CCM.0b013e31826571f2.

[11] Jammer I, Ahmad T, Aldecoa C, Koulenti D, Goranović T, Grigoras I, et al. Point prevalence of surgical checklist use in Europe: relationship with hospital mortality. Br J Anaesth 2015;114:801-7. http://dx.doi.org/10.1093/bja/ aeu460.

[12] Neily J, Mills PD, Young-Xu Y, Carney BT, West P, Berger DH, et al. Association between implementation of a medical team training program and surgica mortality. JAMA 2010;304:1693-700. http://dx.doi.org/10.1001 jama.2010.1506.

[13] Haynes AB, Weiser TG, Berry WR, Lipsitz SR, Breizat A-HS, Dellinger EP, et al. A surgical safety checklist to reduce morbidity and mortality in a global population. N Engl J Med 2009;360:491-9. http://dx.doi.org/10.1056/ NEJMsa0810119.

[14] WHO Guidelines for safe surgery 2009: safe surgery saves lives. Geneva: World Health Organization; 2009 [accessed May 11, 2015]http://www.ncbi. nlm.nih.gov/books/NBK143243.

[15] Teixeira PGR, Inaba K, Dubose J, Melo N, Bass M, Belzberg H, et al. Measurable outcomes of quality improvement using a daily quality rounds checklist: two-year prospective analysis of sustainability in a surgical intensive care unit. J Trauma Acute Care Surg 2013;75:717-21. http://dx.doi.org/10.1097/ TA.0b013e327b61829.

[16] Dubose J, Teixeira PGR, Inaba K, Lam L, Talving P, Putty B, et al. Measurable outcomes of quality improvement using a daily quality rounds checklist: oneyear analysis in a trauma intensive care unit with sustained ventilatorassociated pneumonia reduction. J Trauma 2010;69:855-60. http:// dx.doi.org/10.1097/TA.0b013e3181c4526f.

[17] Centofanti JE, Duan EH, Hoad NC, Swinton ME, Perri D, Waugh L, et al. Use of a daily goals checklist for morning ICU rounds: a mixed-methods study. Crit Care Med 2014;42:1797-803. http://dx.doi.org/10.1097 CCM.0000000000000331.

[18] Weiss CH, Moazed F, McEvoy CA, Singer BD, Szleifer I, Amaral LAN, et al. Prompting physicians to address a daily checklist and process of care and clinical outcomes: a single-site study. Am J Respir Crit Care Med 2011;184:680-6. http://dx.doi.org/10.1164/rccm.201101-00370C.

[19] Frisch A, Miller T, Haag A, Martin-Gill C, Guyette FX, Suffoletto BP. Diagnostic accuracy of a rapid checklist to identify delirium in older patients transported by EMS. Prehospital Emerg Care 2013;17:230-4. http://dx.doi.org/10.3109 10903127.2012.744785.

[20] Munoz-Price LS, Dezfulian C, Wyckoff M, Lenchus JD, Rosalsky M, Birnbach DJ, et al. Effectiveness of stepwise interventions targeted to decrease central catheter-associated bloodstream infections. Crit Care Med 2012:40:1464-9. http://dx.doi.org/10.1097/CCM.0b013e39f5b1823.

[21] Chua C, Wisniewski T, Ramos A, Schlepp M, Fildes JJ, Kuhls DA. Multidisciplinary trauma intensive care unit checklist: impact on infection rates. J Trauma Nurs 2010;17:163-6. http://dx.doi.org/10.1097/JTN.0b013e3181fb38a6.

[22] Byrnes MC, Schuerer DJE, Schallom ME, Sona CS, Mazuski JE, Taylor BE, et al. Implementation of a mandatory checklist of protocols and objectives improves compliance with a wide range of evidence-based intensive care unit practices. Crit Care Med 2009;37:2775-81. http://dx.doi.org/10.1097/ CCM.0b013e3181a96379.

[23] Hewson KM, Burrell AR. A pilot study to test the use of a checklist in a tertiary intensive care unit as a method of ensuring quality processes of care. Anaesth Intensive Care 2006;34:322-8.

[24] Calandra T, Cohen J. International sepsis forum definition of infection in the ICU consensus conference. The international sepsis forum consensus conference on definitions of infection in the intensive care unit. Crit Care Med 2005;33:1538-48.

[25] Aitken LM, Bucknall T, Kent B, Mitchell M, Burmeister E, Keogh SJ. Protocoldirected sedation versus non-protocol-directed sedation to reduce duration of mechanical ventilation in mechanically ventilated intensive care patients. Cochrane Database Syst Rev 2015;1:CD009771. http://dx.doi.org/10.1002/ 14651858.CD009771.pub2.

[26] Youngquist P, Carroll M, Farber M, Macy D, Madrid P, Ronning J, et al. Implementing a ventilator bundle in a community hospital. Jt Comm J Qual Patient Saf 2007;33:219-25.

[27] Exline MC, Ali NA, Zikri N, Mangino JE, Torrence K, Vermillion B, et al. Beyond the bundle - journey of a tertiary care medical intensive care unit to zero central line-associated bloodstream infections. Crit Care 2013;17:R41. http:// dx.doi.org/10.1186/cc12551.

[28] Hooton TM, Bradley SF, Cardenas DD, Colgan R, Geerlings SE, Rice JC, et al. Diagnosis, prevention, and treatment of catheter-associated urinary tract infection in adults: 2009 International Clinical Practice Guidelines from the Infectious Diseases Society of America. Clin Infect Dis 2010;50:625-63.

[29] Burry L, Rose L, McCullagh IJ, Fergusson DA, Ferguson ND, Mehta S. Daily sedation interruption versus no daily sedation interruption for critically ill adult patients requiring invasive mechanical ventilation. Cochrane Database Sys Rev 2014;7:CD009176. http://dx.doi.org/10.1002/14651858.CD009176.pub2.

[30] Leone M, Albanèse J, Garnier F, Sapin C, Barrau K, Bimar M-C, et al. Risk factors of nosocomial catheter-associated urinary tract infection in a polyvalen 
intensive care unit. Intensive Care Med 2003;29:1077-80. http://dx.doi.org/ 10.1007/s00134-003-1767-2.

[31] Dellinger RP, Levy MM, Rhodes A, Annane D, Gerlach H, Opal SM, et al. Surviving sepsis campaign: international guidelines for management of severe sepsis and septic shock: 2012. Crit Care Med 2013;41:580-637. http:// dx.doi.org/10.1097/CCM.0b013e383af1827.

[32] Conroy KM, Elliott D, Burrell AR. Developing content for a process-of-care checklist for use in intensive care units: a dual-method approach to establishing construct validity. BMC Health Serv Res 2013;13:380. http:// dx.doi.org/10.1186/1472-6963-13-380.

[33] Conroy KM, Elliott D, Burrell AR. Validating a process-of-care checklist for intensive care units. Anaesth Intensive Care 2013;41:342-8.

[34] Pronovost P, Berenholtz S, Dorman T, Lipsett PA, Simmonds T, Haraden C. Improving communication in the ICU using daily goals. J Crit Care 2003;18:71-5. http://dx.doi.org/10.1053/jcrc.2003.50008.
[35] Kastrup M, Nolting MJ, Ahlborn R, Braun J-P, Grubitzsch H, Wernecke K-D, et al. An electronic tool for visual feedback to monitor the adherence to quality indicators in intensive care medicine. J Int Med Res 2011;39: 2187-200.

[36] Leone M, Perrin A-S, Granier I, Visintini P, Blasco V, Antonini F, et al. A randomized trial of catheter change and short course of antibiotics for asymptomatic bacteriuria in catheterized ICU patients. Intensive Care Med 2007;33:726-9. http://dx.doi.org/10.1007/s00134-007-0534-1.

[37] Gershengorn HB, Kocher R, Factor P. Management strategies to effect change in intensive care units: lessons from the world of business. Part III. Effectively effecting and sustaining change. Ann Am Thorac Soc 2014;11:454-7. http:// dx.doi.org/10.1513/AnnalsATS. 201311-393AS.

[38] Nguyen Y-L, Wunsch H, Angus DC. Critical care: the impact of organization and management on outcomes. Curr Opin Crit Care 2010;16:487-92. http:/l dx.doi.org/10.1097/MCC.0b013e391802833. 